\title{
RENEWABLES CANNOT BE STORED ECONOMICALLY ON A WELL-RUN POWER SYSTEM
}

\author{
Donald Swift-Hook, \\ Secretary, WREN and Visiting Prof, Kingston University, \\ Woking, Surrey GU21 4XX \\ United Kingdom \\ email: donald@swift-hook.com
}

\section{$\underline{A B S T R A C T}$}

Economic storage on a power system must rely on arbitrage, buying electrical power when it is cheap and selling when it is dear. In practice, this means a store must buy power at night and sell it during the day.

There is no solar power at night [by definition], so solar power cannot be stored economically on a well-run power system. Also renewables [and nuclear] are installed commercially to save fuel but fuel costs the same at night as it does during the day, so there is no arbitrage on fuelsaving to justify storage.

Pumped water storage has always been widely used on power systems and is still the only method that is economic today, although many others have been tried, including fuels cells, compressed air and batteries. Devices for power correction and balancing [e.g. capacitor banks and batteries] may physically involve the storage of energy [just as a mobile phone does] but it is misleading to describe them as methods of power system storage, [just as it would be misleading to call a School bus a fuel transportation system, even though it does transport fuel]. When a power system has different sorts of plant generating - coal, gas, nuclear, wind etc any power being put into storage is from the plant that would need to be switched off [because less power was needed] if storage ceased [e.g. because the store became full or failed]. On a well-run power system, that always has the highest fuel/running cost, but the wind blows free and has zero fuel/running cost, so wind is never [normally] stored unless there is no other plant on line i.e. wind power is the last to be stored.

\section{$1 \quad \underline{\text { INTRODUCTION }}$}

Storing electricity is part of normal power system operation and pumped water is the only system of bulk storage of electricity that has been in use since power systems were first installed (1) and it is still the only system in practical use today. Figure 1 shows the upper storage lake and dam of a 400 MW pumped storage scheme at Cruachan that has been in operation in Scotland since 1965 and Figure 2 shows diagram-matically how such a system operates. $5 \%$ of all EU generation is associated with pumped water storage systems. 
The economics of such a store rely on arbitrage: electricity is put into store (e.g. by pumping water) when it is cheap and re-generated when it is dear.

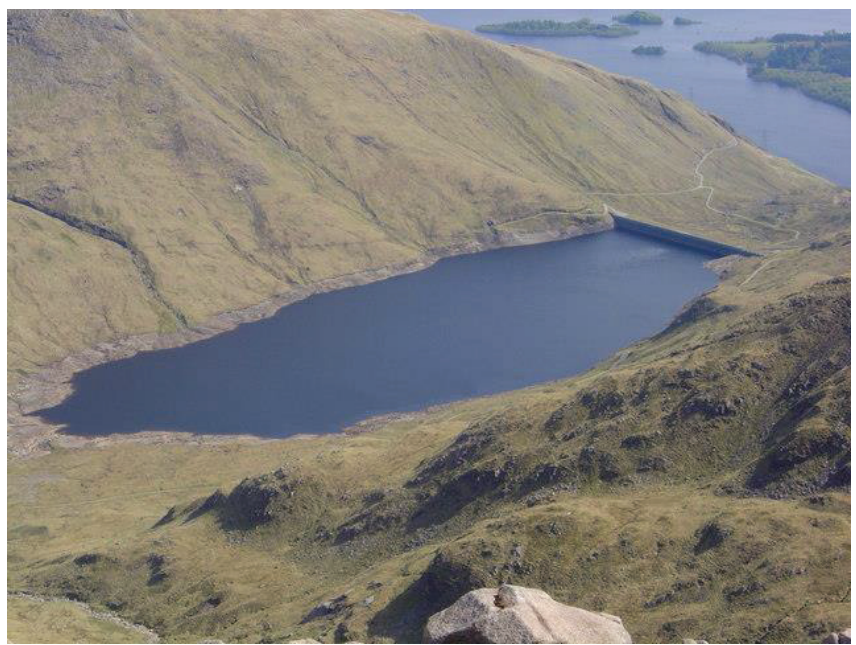

Figure 1. The upper lake and dam at Cruachan, above Loch Awe in Scotland, a $400 \mathrm{MW}$ reversible-pumped water storage scheme commissioned in 1965.

If the extra value of the electricity is sufficient to pay for the cost of the storage plant (pumps, etc) as well as the round-trip loss of energy in pumping and then regenerating (typically $10 \%$ or $20 \%$ being lost in each direction), the system can be economic.

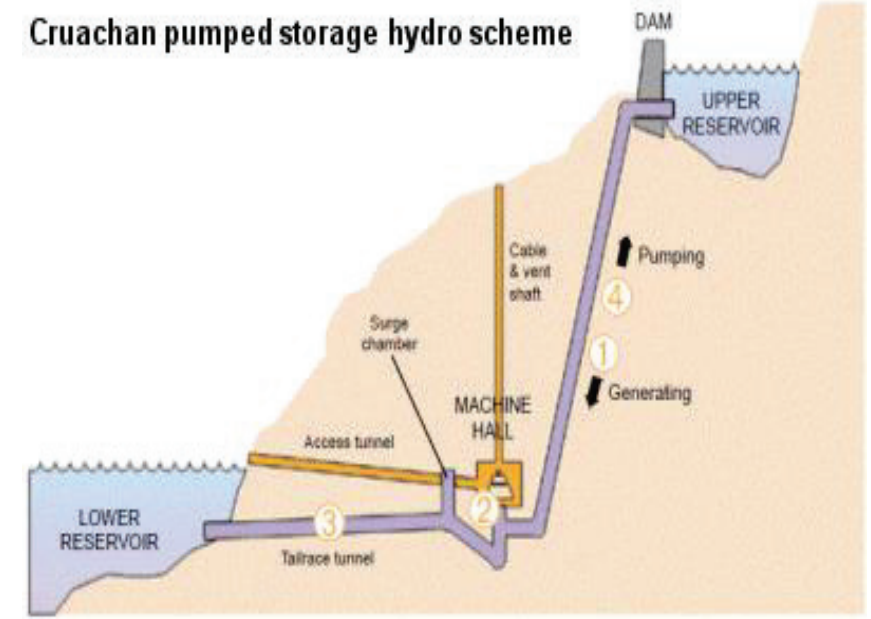

Figure 2. Typical features of a modern pumped water storage facility

On most power systems, this arbitrage between cheap and expensive electricity is between nighttime and day-time generation.

\section{$3 \quad$ SOLAR POWER}

An immediate consequence is that solar power cannot be stored economically on a power system because there is no sunshine (by definition) at night and therefore no solar power when power needs to be stored.

When solar photovoltaic power plant stands alone, not grid-connected, storage is needed to provide power when the sun does not shine. A typical example is shown in Fig 3 of a solar 
powered garden light, which includes a battery that is charged during the day by a solar cell while the sun shines and then can provide illumination when it discharges through a small light bulb at night. It is cheaper to provide a battery to store as much as 12 hours of electricity than it is to extend the power system for a mains-connection to the electricity network.

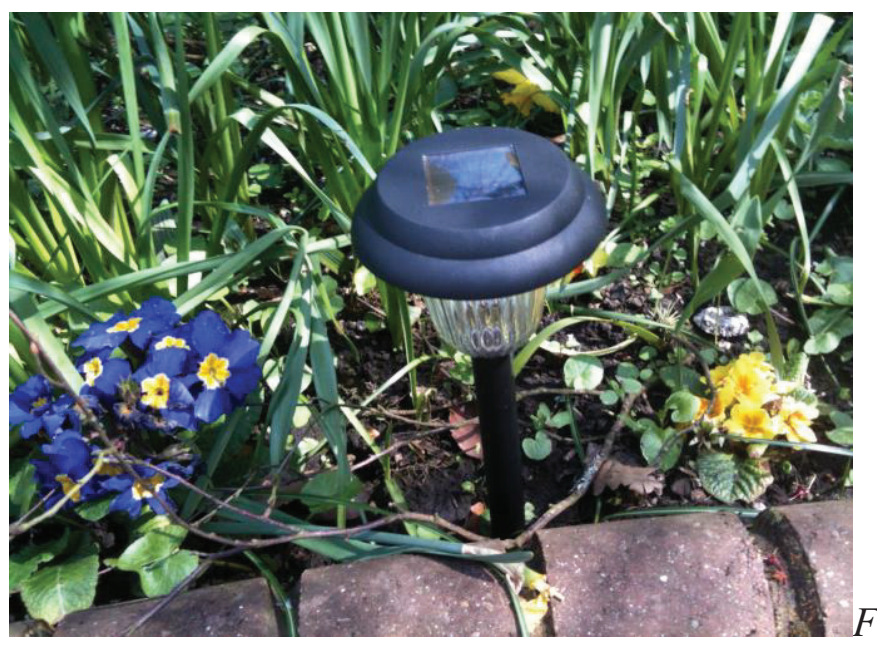

Figure 3. With no mains supply, a garden light has a solar cell on top to charge a battery during the day which discharges through a small light bulb to provide illumination at night.

So it is not to be said that you cannot store solar power, only that you cannot do so economically when you are mains connected. Recommendations to the contrary are often made and, although they are clearly physically possible, they are simply not economic.

\section{4}

\section{FUEL SAVING}

Avoiding emissions to limit global warming does not have any direct financial advantage for a generator and nor is the commercial justification for renewables normally to provide generating capacity: it is to save fuel.

Those countries with the greatest interest in saving fuel are those with the greatest fuel production /consumption, so it is no co-incidence that China, the USA and India, who are amongst the greatest fuel producers, are also installing the most wind power, more than half of the worlds capacity between them (3). The EU too relies heavily on fuel imports, so it too has a great interest in installing wind power, to save the need for fuel imports.

Having saved a certain amount of fuel by using wind energy, to put the electricity into a store and then regenerate it involves losses, so storage must always waste fuel and less fuel will have been saved at the end of the storage process than without it. There is no variation in the cost of fuel between when the wind blows and does not blow to counter-balance this loss and allow arbitrage. So storing wind energy must always expect to waste money as well as fuel. The same is true for other renewables. This means that storage cannot be economic for a fuel saver and the suggestion that storage should be installed with renewables is unrealistic. 
In 1994, Ter-Gazarian (2) described many other methods of storage based on many different physical principles, including various types of thermal energy storage, fly wheels, compressed air, various electro-chemical systems, capacitor banks and superconducting coils.

Few methods have been added to this list since then and, despite continuing research activities and development projects, no new practical systems have emerged for large-scale use. Pumped water is still the only realistic method to be installed for electrical energy storage on power systems today. Pumped air has been advocated instead of pumped water and two commercial scale demonstration projects were put into operation in the last century, a 290 MW scheme at Huntorf in Germany in 1978 and a smaller 110 MW plant 13 years later at McIntosh, Alabama. Neither of these proved economic but studies have continued, including recent experimental installations at Gaines in Texas in 2012 generating 2 MW and at Seabrook, New Hampshire in 2013 generating 1.65 MW. Nothing on a commercial scale has materialised.

Fuel cells, too, have been widely advocated for use on power systems. The first practical fuel cell systems were used in the first satellites and then on a much larger scale in the Apollo space missions, Figure 4, but they have not proved commercially viable for Earth-bound applications.

Large banks of lead-acid batteries have been used to power submarines silently for nearly 100 years. Today, huge efforts are going into the development of lithium-ion batteries for electronic applications (because they have much higher energy density, much lower loss of charge and no memory effect) and they are making some inroads for vehicle applications. On power systems, batteries are used for control and balancing purposes but they are far too expensive to consider for bulk energy storage.

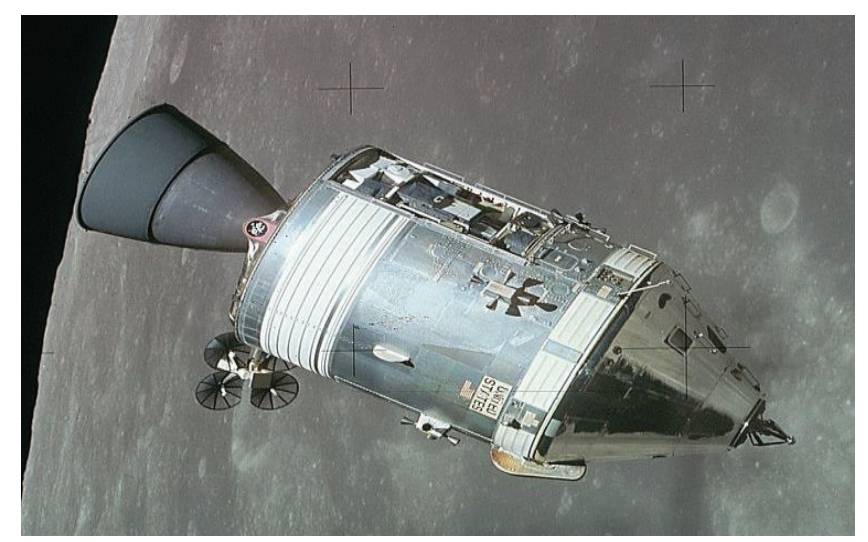

Figure 4. Alkaline fuel cells have been used by NASA in the Apollo missions (shown here) and in the Space Shuttles

A great deal of confusion is being created by battery enthusiasts who assert that the variability of wind makes energy storage essential and suggest that new developments are leading to batteries being widely used for energy storage on power systems. This is misleading terminology.

Batteries are being introduced on a widespread basis to enhance the frequency response of power systems but that is control and balancing. The physical processes certainly involve the storage of energy, just as charging a mobile telephone does, but energy storage [putting energy in and taking it out later] is not what they are for in either case.

UK's National Grid Plc recently tendered for Enhanced Frequency-Response equipment and, of the 64 sites that bid, 61 were for batteries. Successful companies included EdF Energy 
Renewables Ltd., Vattenfall AB, EON SE, Low Carbon, Element Power Ltd, RES and Belectric Solar Ltd. This is the first time that batteries will have been introduced onto the UK power system on such a scale.

The amount of energy stored is not significant in bulk energy terms - they will not be called upon to supply electricity for more than 15 minutes - but it is their ability to do so at 1 second's notice that is the attraction, to enhance the power system's frequency response. It is misleading to claim that such units are for power system energy storage when they are only for power system control or balancing.

\section{$7 \quad$ STORAGE VIS À VIS WIND POWER.}

It has been pointed out that storage cannot be economically associated with solar power but nor can it be with wind power. There are several obvious mistakes that are frequently made.

For instance, it is often suggested that storage would be valuable to transform intermittent wind into base-load generation. However, during periods of base-load, capacity must be standing idle and freely available for generation. The value of yet more capacity at such a time is clearly negligible, so the installation of storage or, indeed, any other type of power plant, cannot be justified economically then and the idea of transforming intermittent wind into base-load generation is misconceived. [The times when capacity is needed are at peak periods but these are so brief that, again, storage cannot be justified then, unless it is competitive with cheap gas turbine peaking plant and that is totally unrealistic].

Storage and wind power are not compatible contractually (4). The wind only blows for a fraction of the time, typically around one third on average in the UK, although there are rarely periods when there is no wind at all. Any associated storage would therefore find wind taking three times as long and therefore three times the cost to be stored as nuclear or any other continuously available type of power would. [This argument applies to any other type of power plant on a power system. If the storage were associated with just one plant, it too would be out of service whenever the plant was. The store should be associated with the whole power system.]

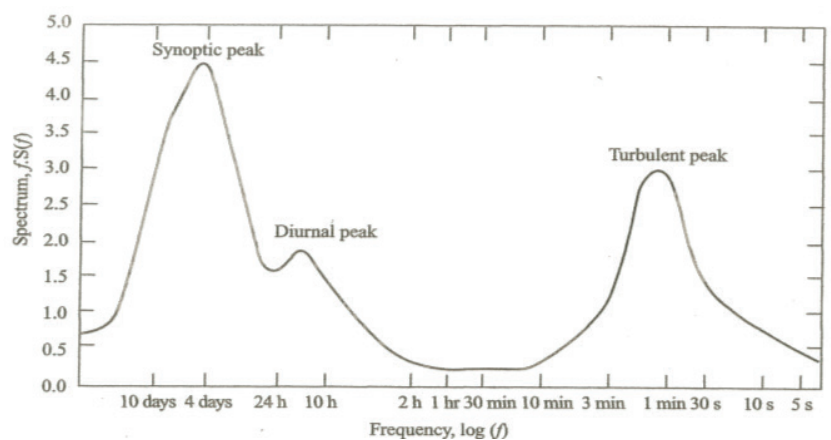

Figure 5. The classical frequency spectrum measured by van der Hoven at Brookhaven National Labs on Long Is.

The classic work of van der Hoven (Figure 4) showed three peaks in the wind frequency spectrum: one due to the local turbulence (1 to $2 \mathrm{~min}$ ), a small diurnal (day to night) peak and a broad synoptic peak from 2 to 10 days when the wind blows for up to 10 days (as a weather pattern passes) and ceases for up to 10 days. If a store cannot cope with 10 days of wind it is not effectively tackling the wind storage problem. A store coping with 10 days of wind must be up to 
20 times larger and more costly than a typical night-to-day store making effective storage for wind power prohibitively expensive.

On a more practical note, enthusiasts who claim that wind power needs storage to cope with it's intermittency manage to ignore the fact that, with more than $300 \mathrm{GW}$ of wind power generating capacity installed - and there is now more wind capacity operating than nuclear, in the UK and the EU and world-wide - no wind-farm has ever had to install a storage plant alongside it.

Having shown that to store wind power is very costly, let us consider when it is likely to happen on a power system. It has been pointed out that power systems use storage very widely (1), with or without wind power on them, and it might then be thought that, when electricity is being put into a store, typically during base-load periods at night, and the wind happens to be blowing at the same time, wind is as likely as any other source of power to be stored or perhaps even more likely. More careful consideration shows that this is not the case.

To discover which source of energy is being stored at any particular time when many different types of power plant are on line, we need to look at the state of the power system with and without storage. The difference between the two tells us which power is being stored. The power plant, which would need to be switched off if storage ceased (because the store failed or became full) would be the power plant that was filling the store.

The plant to be switched off on a well run power system, which always uses the cheapest power available, would be the dearest generation on the system at the time. The "wind blows free" and has zero marginal cost so wind will always be amongst the cheapest plant and never the dearest, unless the cheapest generation is also the dearest, that is to say wind is the only generation left on the system.

A proviso is that some plant may have less than zero marginal cost and be prepared to pay to stay on line. Combined Heat and Power may have periods [e.g. in the early hours of a cold winter night] when heat is needed but no electric lights and it can't do one without the other. Nuclear and other plant may find thermal cycling very damaging and be prepared to pay to avoid it. With these provisos, it can be said that wind is the last to be stored.

1. Despite continuing research activities and other development projects, pumped water is still the only system of bulk energy storage being installed on power systems today.

2. Energy storage is economically justified by arbitrage between cheap [night-time] and more expensive [day-time] electricity.

3. Pumped waster storage plant can also provide many control and balancing services such as spinning reserve but these are quite distinct from storage; batteries, capacitor banks and other 
plant can also offer such control and balancing functions but it is misleading and confusing to claim that they are "for power system energy storage".

4. With no solar power at night, of pv solar power cannot be stored economically on a power system.

5. Contrary to frequent misunderstandings, the installation of storage cannot be justified on a power system to store wind energy either. Storage and wind power are contractually not compatible.

6. Wind power is to save fuel and to store wind power would waste fuel on round-trip losses. Storage cannot be economic for a fuel saver

7. Wind only blows for one third of the time on average, so it will take 3 time as long and cost 3 time as much to store only wind compared with nuclear or any other continuously available type of power.

8. The wind frequently blows for up to 10 days at a time and a store of such capacity would cost 20 times as much as current day/night energy storage costs.

9. If storage is already installed on a well-run power system with various types of generation, normally wind is the last to be stored.

$10 \quad$ REFERENCES

(1) Swift-Hook, D.T., Grid-connected intermittent renewables are the last to be stored, Renewable Energy, Vol. 35, p.1967, 2010

(2) Ter-Gazarian, A., Energy storage for power systems Vol. 6 in Swift hook DT editor IEE Energy Series. London: Peter Peregrinus, 1994

(3) Swift-Hook, D.T., The case for renewables apart from global warming, Renewable Energy, Vol. 49, p. 147-150, 2013

(4) Swift-Hook, D.T., Wind energy really is the last to be stored and solar energy cannot be stored economically, Renewable Energy, Vol. 50, p. 971-976, 2013 